\title{
Enhancing the Cash Point using Multimode Biometric System
}

\author{
Mr. T. Karthikeyan'1 M.E., Ms. Aarthi. S², Ms. Amirtha. P2, Ms. Divya. ${ }^{2}$, Ms. Sowndarya. S \\ ${ }^{1}$ Assistant Professor, 2 UG Students \\ 1,2Department of Electronic and Communication Engineering, \\ 1,2Sri Ranganathar Institute of Engineering and Technology, Coimbatore, Tamil Nadu, India
}

\begin{abstract}
How to cite this paper: Mr. T. Karthikeyan | Ms. Aarthi. S | Ms. Amirtha. P | Ms. Divya. R | Ms. Sowndarya. $S$ "Enhancing the Cash Point using Multimode Biometric System" Published in International Journal of Trend in Scientific Research and Development (ijtsrd), ISSN: 24566470, Volume-3 | Issue-3 , April 2019, pp.353-358, URL: http://www.ijtsrd.co $\mathrm{m} /$ papers/ijtsrd217 68.pdf

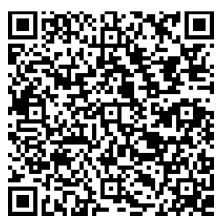

IITSRD21768
\end{abstract}

Copyright (C) 2019 by author(s) and International Journal of Trend in Scientific Research and Development Journal. This is an Open Access article distributed under the terms of the Creative Commons

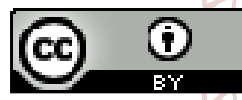
Attribution License (CC BY 4.0) (http://creativecommons.org/licenses/ by $/ 4.0$ )

\section{INTRODUCTION}

A $24 \times 7$ self-banking service has made the ATM the heart of banking. The surplus use of ATMs has not only leaded to an increase in their number but has also increased fraudulent attacks on the ATMs. This calls for the biometric systems to be integrated in the traditional ATM.

There are different thefts being taken place. High level of security is essential for a safe and secure environment. We can distinguish the different types of thefts. There are three types of theft taking place mainly:

$>$ Identity theft

$>$ Logical theft

$>$ Physical theft

\section{$>$ IDENTITY THEFT:}

Identity theft refers to the category of crimes that capture the data used by a consumer to authenticate themselves at a self-service terminal to enable their financial service. The most frequent attack vectors in this category include card skimming, card traping, and card sniffing.

\section{$>$ LOGICAL THEFT:}

Logical theft of valuable media refers to the category of crimes that are used to steal cash or other valuable media from the ATM using methods which do not physically breach the cash enclosure.
Frauds attacking the automated teller machine have increased over the decade which has motivated us to use the biometrics for personal identification to procure high level of security and accuracy This paper describes a system that replaces the ATM cards and PINs by the physiological biometric face and iris hentication. In this system during enrolment the genuine user's face and iris distinguish between real legitimate trait and fake samples. If a fake biometric is recognized a GSM module connected to the controller will message OTP by the can either withdraw or deposit cash or check his/her balance. We have included Keywords: ATM-automated teller machine, GSM-Global systems for mobiles, Biometric, OTP-One time password

Typically, these attacks fall into three main categories: 1. Black box attacks

2. Malware in network.

3. Malware installed on the ATM.

\section{$>$ PHYSICAL THEFT:}

Physical theft of valuable media-the category of crimes that are used to steal cash or other valuable media from the ATM using methods which physically breach the cash enclosure. This category includes all of the traditional robbery techniques that can be used to open a safe, and includes emerging trends such as the use of explosives. It causes a major disaster to the environment.

\section{LITERATURE SURVEY}

The author in "ATM TRANSACTION SECURITY USING FINGERPRINT RECOGNITION "Built an ATM based on fingerprint verification and incorporated the fingerprints of the users into the database of the respective banks to simulate it for ATM operations. Due to the lack of the fingerprint matching algorithm it proved to be inefficient.

In the paper "SMART ATM SECURITY SYSTEM USING FPR, GSM, GPS" a system which performed authentication by including both the fingerprint and GSM technology into the traditional PIN based ATM system. 
In the paper "SECURITY ATM TRANSACTION WITH SMS ALERT" an algorithm was constructed based on Short Message Service (SMS) verification to enhance the ATM authentication system. Authors in secured the system using fingerprint and iris, along with this the system used RFID reader module, developed a RFID card as input to the microcontroller for identification and a GSM module to send messages involving three options (yes, no, action) to the authorized user's mobile. Authors in proposed an efficient system which used the method of analyzing iris patterns for user identification In a system using iris recognition and palm vein recognition technology was proposed in order to avoid crimes in the ATM transactions.

Authors in "A NOVEL METHOD TO ENHANCE THE SECURITY OF ATM USING BIOMETRIC" proposed a system which incorporated facial recognition in the traditional ATM for authentication of users. In authors used Hough Transform for iris recognition in order to isolate the unique features of particular shape within an image. In an Advanced Encryption Standard (AES) algorithm was used in order to enhance the security of the ATM transaction. Described a system which used face as a key, The system performed facial recognition using Principal Component Analysis for facial recognition along with OTP for security of transaction.

The word "Biometrics" comes from the Greek language and is derived from the words "bio "means life and "metric" means to be measure, so biometrics is a field of science and technology used to be measure life characteristics. Biometrics System uses physical (like fingerprint and retina) and behavioral (like voice and handwriting) parameters for person.

\section{EXISTING SYSTEM}

\section{FINGERPRINT:}

Biometric data are unique for each individual person, even two identical twins. Basically we can use physical parameters than behavioural because behavioural parameters are changed with age and environment whereas physical parameters never changed during whole life. Fingerprint matching techniques are divided into three main types:

$$
\begin{aligned}
& >\text { Correlation based matching, } \\
& >\text { Minutiae based matching, and } \\
& >\text { Pattern based matching. }
\end{aligned}
$$

\section{FACE RECOGNITION:}

The proposed system uses skin tone extraction, facial feature exaction and feature extraction is done using LBP.

1. Pre Processing

2. Feature Extraction

3. Statistical Feature

$>$ Mean

$>$ Standard deviation

$>$ Variance

$>$ Kurtosis

\section{LBP ALGORITHM}

$>$ Computationally efficient.

Texture: Variation of data at scales smaller than the scale of interest

Descriptor: Compact representation that captures at least one essential characteristic of the sample under examination
$>$ Rare technique that is good, fast and cheap

$>$ LBP is a simple yet very efficient texture operator which labels the pixels of an image by thresholding the neighborhood of each pixel and considers the result as a binary number.

\section{PROPOSEDSYSTEM}

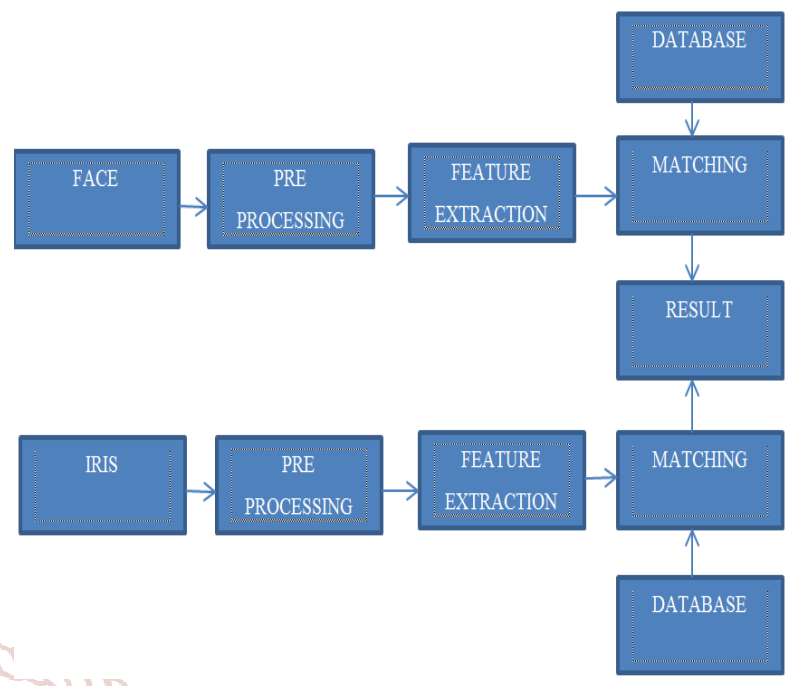

Fig (a): Block diagram of proposed system

\section{IRIS PROCESS}

Recognition of humans based on characteristic eye features has taken a significant place in security and identification systems in the past two decades. The complex pattern of the iris, that is unique to an eye, makes iris a great biometric descriptor. The first step in the process of the biometric identification based on iris is its localization in an image. The shape of the iris, its size, position, shades from the light sources and eyelashes make this process difficult.

\section{Pre processing}

The way IDO (Integro differential operator) works, it cannot be tolerant to reflection spots and uneven high intensity pixels present in the iris image. The reflection spots in iris images cover portions of the image that causes hindrance in the iris detection process.

\section{Iris's inner boundary (pupil) localization}

To localize pupil using IDO, the image pixels on which the IDO is applied are identified first otherwise it may take much large time in localizing pupil. These identified pixels are the potential centers of pupil circle (pupil-centers).

\section{Binary Image clean-up:}

The noise in the binaries image is removed using image erosion for black objects which is a morphological operation. The erosion operation uses a structuring element of type disk because pupil is circular region. Removing pixels close to image border: It is certain in every iris image that pupil cannot be touching the image border as pupil is surrounded by iris region. So, some pixels closer to the image border can be discarded as they cannot be potential pupil-centers.

\section{Iris's outer boundary localization}

Iris's outer boundary localization may be hurdled by eyelids, eyelashes, reflections and low contrast between the iris and sclera. The reflections and uneven high intensity values have already been removed after the image pre-processing step. 


\section{Define iris search region:}

The iris search area is defined by the pupil center, radii range of the iris's outer boundary and a small area around pupil-center which contains potential candidate pixels for centers of iris's outer boundary circle.

\section{SOFTWARE ANALYSIS}

\section{MATLAB:}

The name MATLAB stands for Matrix Laboratory. MATLAB was written originally to provide easy access to matrix software developed by the LINPACK (linear system package) and EISPACK (Eigen system package) projects. MATLAB is a high-performance language for technical computing. It integrates computation, visualization, and programming environment.

\section{MATLAB'S POWER OF MATHEMATICALCOMPUTATIONS:}

MATLAB is used in every facet of computational mathematics. Following are some commonly used mathematical calculations where it is used most commonly

$>$ Dealing with Matrices and Arrays

$>$ 2-D and 3-D Plotting and graphics

$>$ Linear Algebra

$>$ Algebraic Equations

$>$ Non-linear Functions

$>$ Statistics

$>$ Data Analysis

$>$ Calculus and Differential Equations

$>$ Numerical Calculations

$>$ Integration

$>$ Transforms

$>$ Curve Fitting

$>$ Various other special functions

FEATURESOF MATLAB:

Following are the basic features of MATLAB

$>$ It is a high-level language for numerical computation, visualization and application development.

$>$ It also provides an interactive environment for iterative exploration, design and problem solving

\section{USESOF MATLAB:}

$>$ Signal Processing and Communications

$>$ Image and Video Processing

$>$ Control Systems

$>$ Test and Measurement

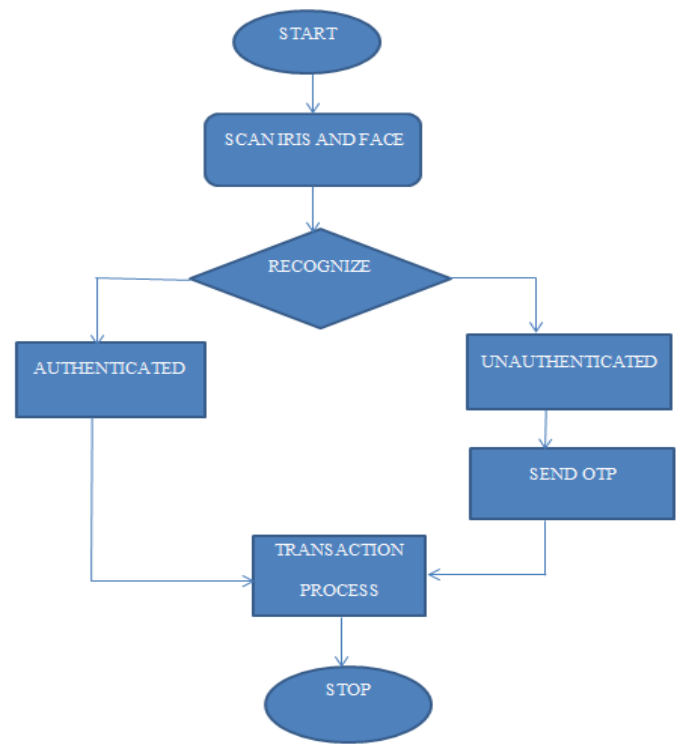

Fig (b): Flow chart
It allows matrix manipulations; plotting of functions and data; implementation of algorithms; creation of user interfaces; interfacing with programs written in other languages, including $\mathrm{C}, \mathrm{C}++$, Java, and FORTRAN; analyse data; develop algorithms; and create models and applications.

It has numerous built-in commands and math functions that help you in mathematical calculations, generating plots, and performing numerical methods.

MATLAB (matrix laboratory) is a multi Paradigm numerical computing environment. A propriety programming language developed by Math Works.

\section{HARDWARE ANALYSIS}

\section{ARUDINO}

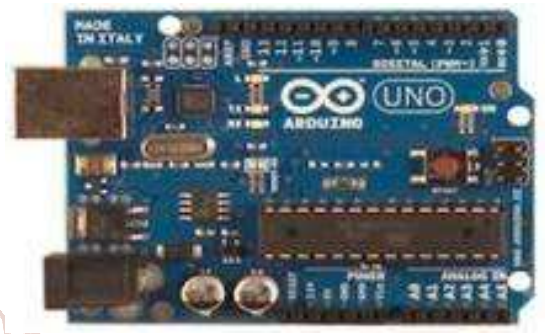

Fig(c): Arduino Board

Arduino is an open-source electronics platform based on easy-to-use hardware and software. Arduino boards are able to read inputs -light on a sensor, a finger on a button, or a Twitter message - and turn it into an output - activating a motor, turning on an LED, publishing something online.

\section{Solentiric}

The Arduino Uno is a microcontroller board based on the ATmega328. It has 14 digital input/output pins (of which 6 can be used as PWM outputs), 6 analog inputs, a $16 \mathrm{MHz}$ crystal oscillator, a USB connection, a power jack, an ICSP header, and a reset button.

Arduino is an open-source electronics platform based on easy-to-use hardware and software.

Arduino boards are able to read inputs - light on a sensor, a finger on a button, or a Twitter message - and turn it into an output - activating a motor, turning on an LED, publishing something online.

\section{GSM}

GSM (Global System for Mobile communication) is a digital mobile network that is widely used by mobile phone users in Europe and other parts of the world.GSM uses a variation of time division multiple access (TDMA) and is the most widely used of the three digital wireless telephony technology

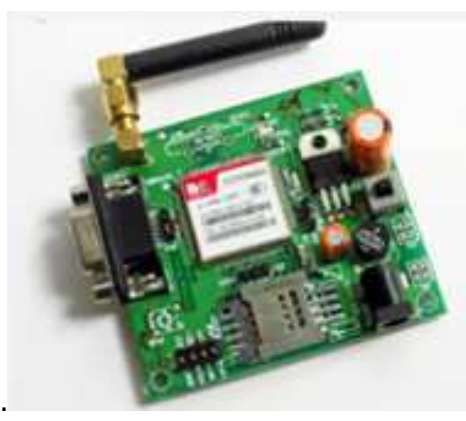

Fig (d): GSM network organization 


\section{$>$ LIQUID CRYSTAL DISPLAY (LCD)}

LCD Modules can present textual information to user. It's like a cheap "monitor" that you can hook in all of your gadgets. They come in various types. The most popular one is $16 \times 2$ LCD Module LCD (liquid crystal display) is the technology used for displays in notebook and other smaller computers. Like light-emitting diode (LED) and gas-plasma technologies, LCDs allow displays to be much thinner than cathode ray tube (CRT) technology.

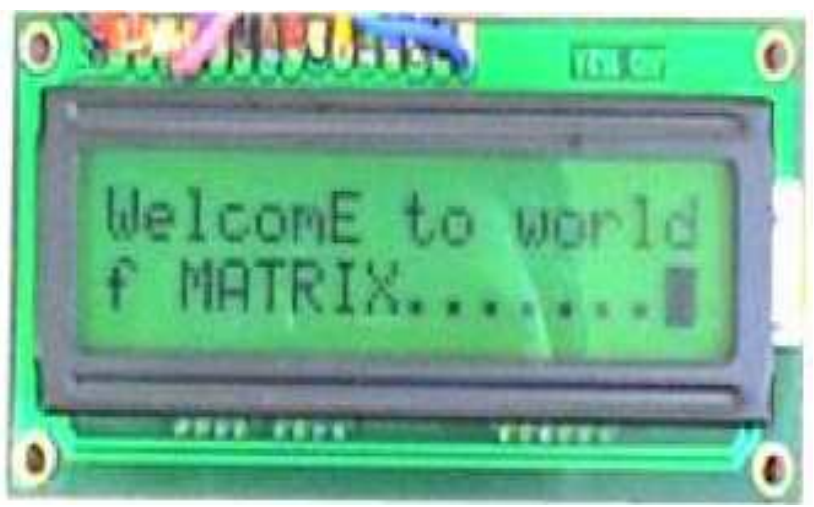

Fig (e): 16X2 LCD MODULE

LCDs consume much less power than LED and gas-display displays because they work on the principle of blocking light rather than emitting it.

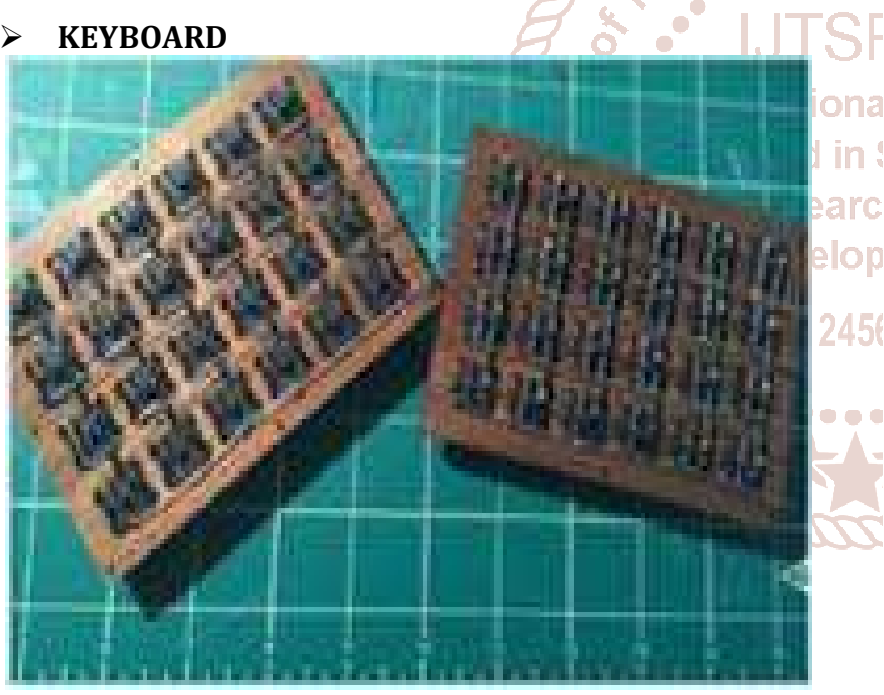

Fig (f): Keyboard

A computer keyboard is one of the primary input devices used with a computer. Similar to an electric typewriter, a keyboard is composed of buttons that create letters, numbers, and symbols, as well as perform other functions. The following sections provide more indepth information and answers to some of the more frequently asked questions about the keyboard.

On most computers, a keyboard is the primary text input device. (The mouse is also a primary input device but lacks the ability to easily transmit textual information.) The keyboard also contains certain standard function keys, such as the Escape key, tab and cursor movement keys, shift and control keys, and sometimes other manufacturer-customized keys.
The computer keyboard uses the same key arrangement as the mechanical and electronic typewriter keyboards that preceded the computer. The standard arrangement of alphabetic keys is known as the Qwerty (pronounced KWEHR-tee) keyboard, its name deriving from the arrangement of the five keys at the upper left of the three rows of alphabetic keys.

\section{$>$ CONNECTING WIRES}

Connecting wires allows an electric current to travel from one part of the circuit to another. A wire is single usually cylindrical, flexible strand or rod of metal. Electricity needs a medium to travel. It is used to make a low resistance electrical connection between two devices.

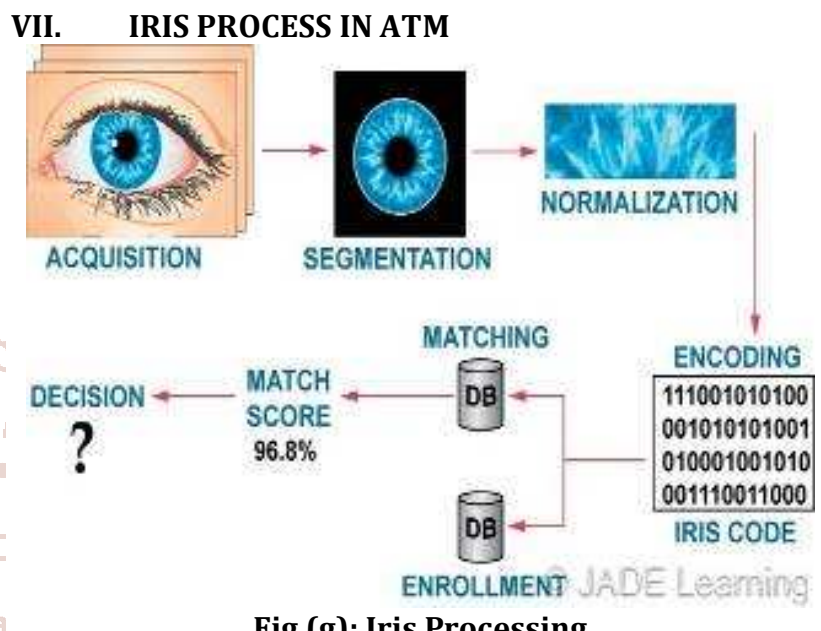

\section{EXPERIMENTAL SETUP AND OBSERVATION}

$>$ This is the image of matlab version 13(b) with 64 bits

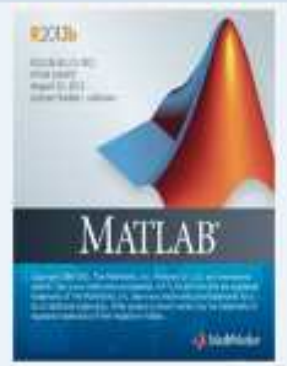

Fig (h): Matlab version

$>$ The below image is the recognition of face of a person accessing atm.

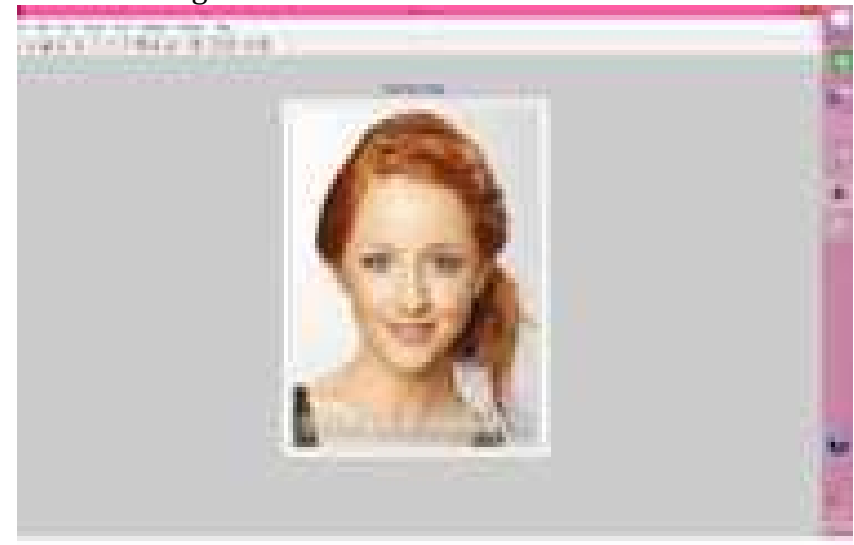

Fig (i): Face Recognition 
International Journal of Trend in Scientific Research and Development (IJTSRD) @ www.ijtsrd.com eISSN: 2456-6470

$>$ It is the observed black and white image of the recognized face given before

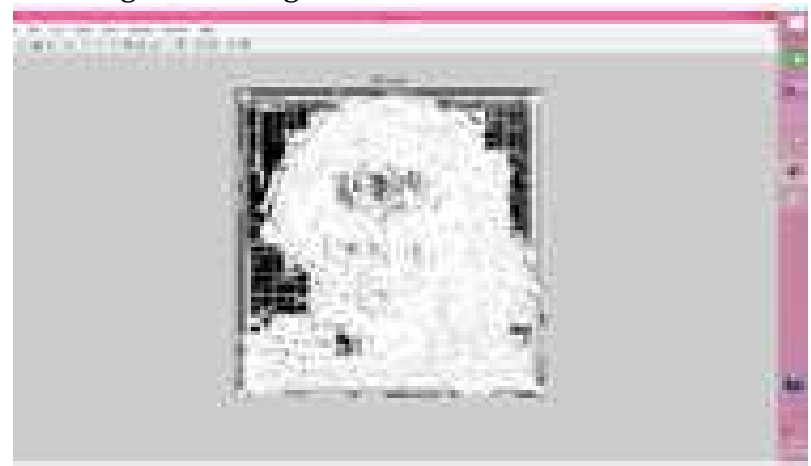

Fig (j): Converted Image

The iris of the same person stated above

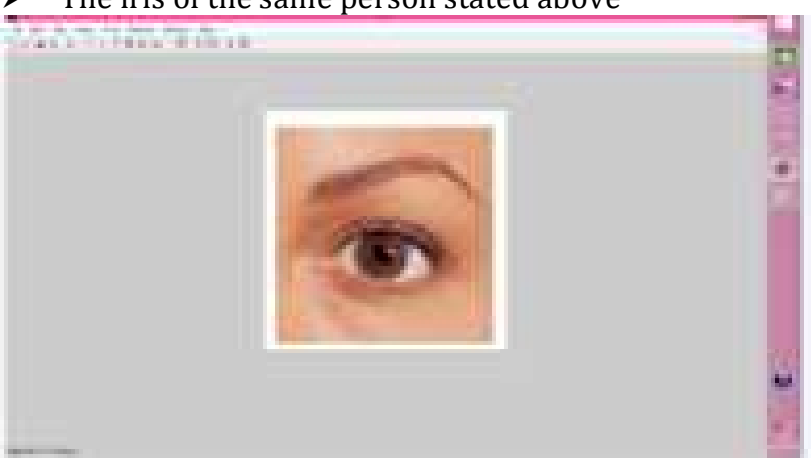

Fig (k): Iris Recognition

The scanning process of the iris by matlab software.

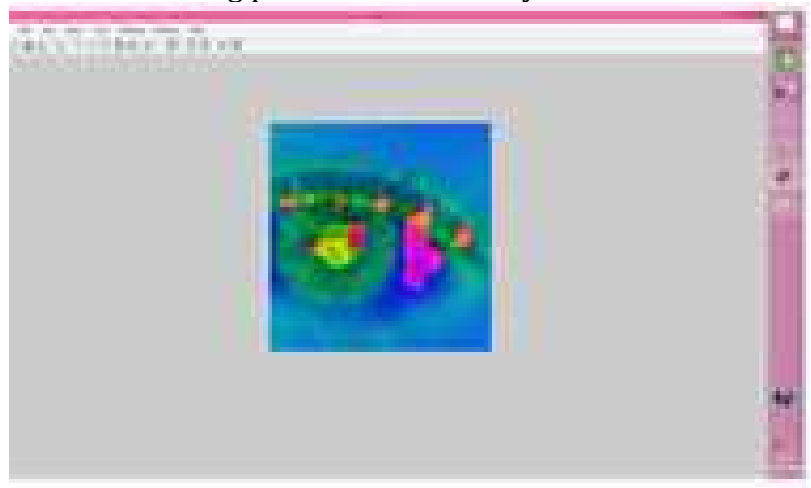

Fig (1): Iris Scanning

The graphical representation of pixel variation

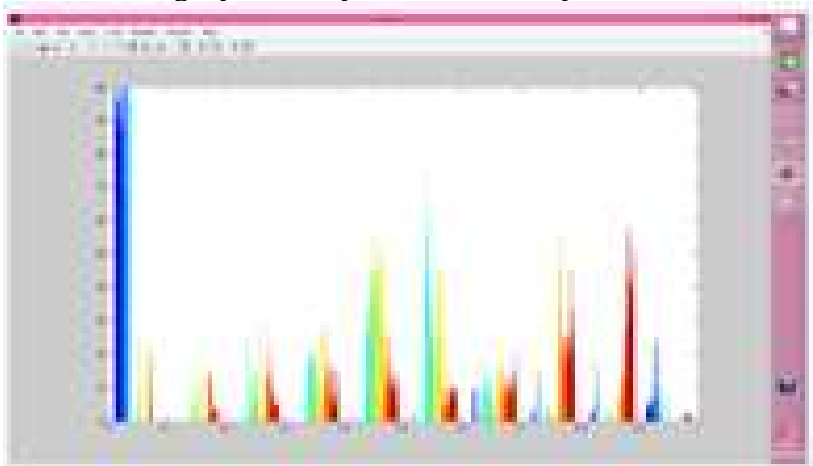

Fig (m): Pixel variation

\section{COMPARASION}

FALSE REJECTION RATIO:

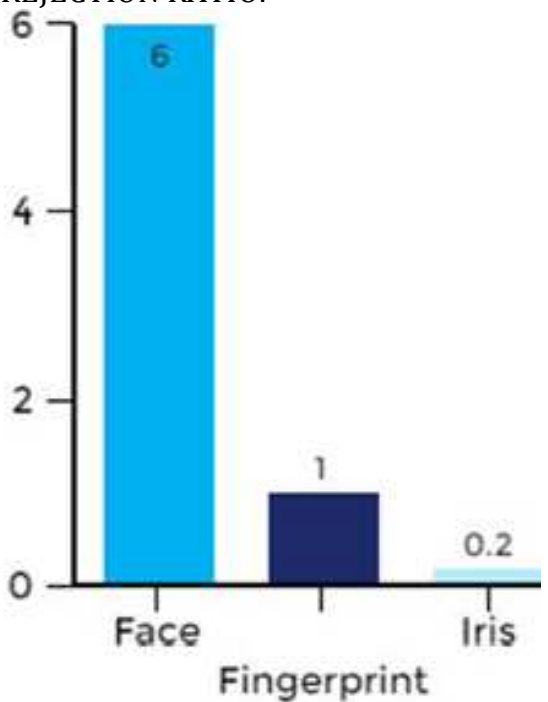

Fig (n): Comparision Ratio

When an authorized user approaches the ATM the false rejection rate of iris is very low.

\section{Ie $\mathbf{X} . \quad$ RESULT}

1. If the person is authenticated we can collect cash from the atm.The below figure shows the matched persons details.

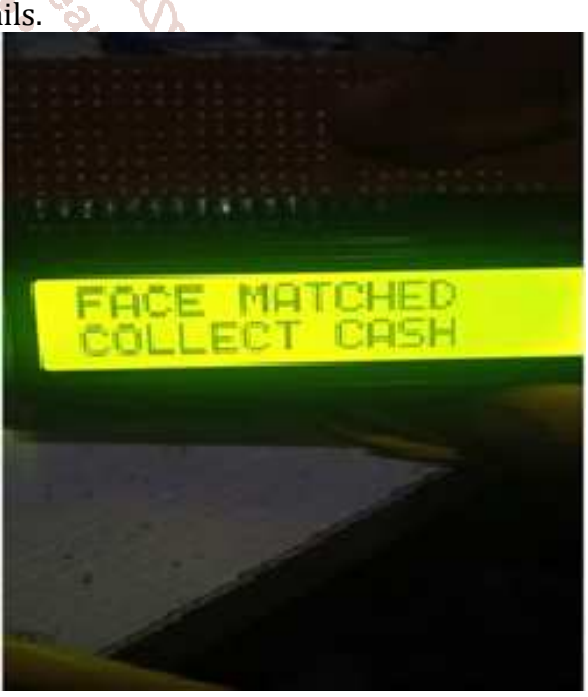

2. If the person is unauthenticated no money is obtained
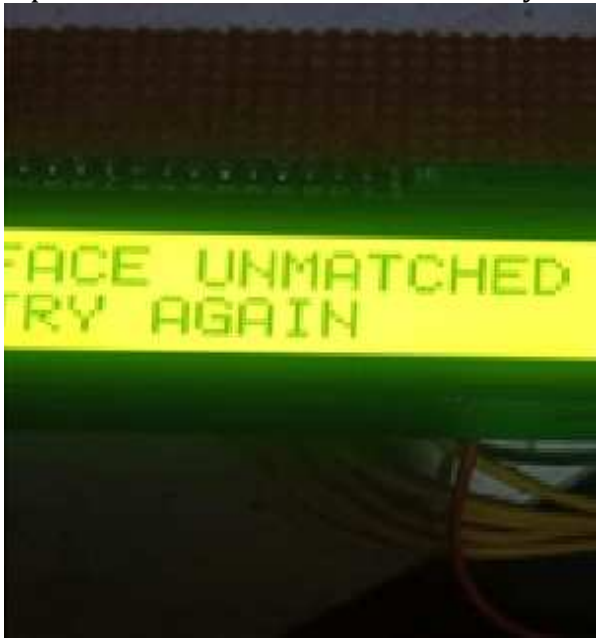
3. If a second user want to use the atm he has to enter the OTP.

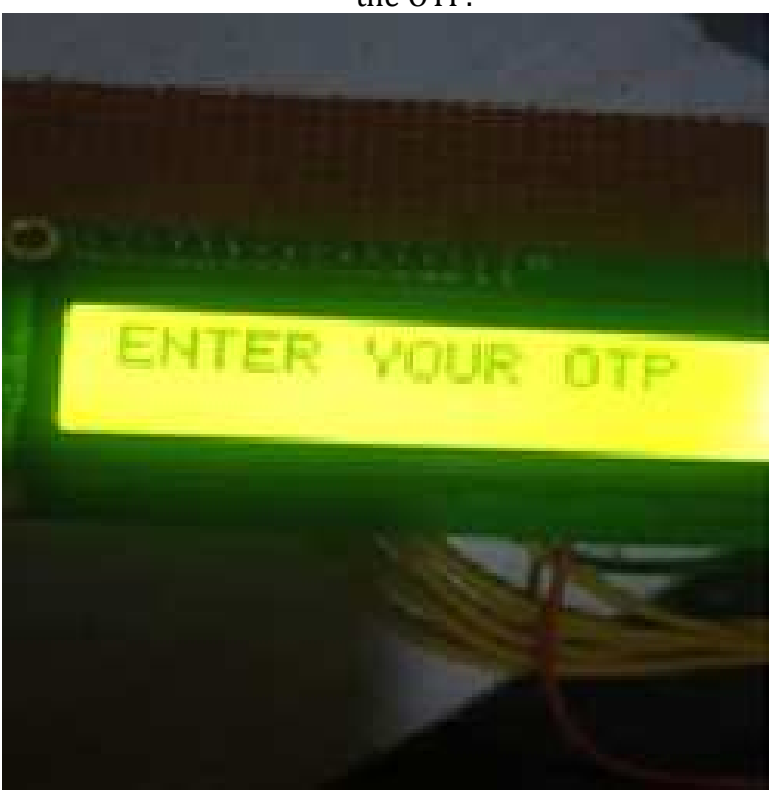

OTP will be sent to the authorised person The second user has to fetch the OTP from the authorised person.Only then he /she can collect the amount from the ATM.

\section{CONCLUSION}

The proposed system based on arudino microcontroller is found to be multipurpose. Moreover the development board used is opensource, hence this project providesan option for future enhancements. It uses GSM technology which is very popular and reliable. We have provided a way to catch hold of the thief which plays an important role.

\section{REFERENCE}

[1] Bharati M Nelligani, Dr. N V Uma Reddy, Mr. Nithin Awasti, “SMART ATM SECURITY SYSTEM USING FPR, GSM, GPS".

[2] Givens. G. H, Beveridge. J. R, Phillips. P. J, Draper. B, Lui. Y. M, Bolme. D "INTRODUCTION TO FACE RECOGNITION AND EVALUATION OF ALGORITHM PERFORMANCE".

[3] KrishanTuli, Gurpreetkaur, “ATM SAFETY AND SECURITY".

[4] Narmada,. D. J. V. Priyadarsini, "DESIGN AND IMPLEMENTATION OF SECURITY BASED ATM USING ARM 11.

[5] Renee. GJebaline, S. Gomathi, “A NOVEL METHOD TO ENHANCE THE SECURITY OF ATM USING BIOMETRICS".

[6] Sambartaray, Souvikdas, Dr. AnindyaSen, “AN INTELLIGENT VISION SYSTEM FOR MONITORING SECURITY AND SURVEILLANCE OF ATM".

[7] SudhirGoswami, JyotiGoswami, Nagreshkumar, "UNUSUAL EVENT DETECTION IN LOW RESOLUTION VIDEO FOR ENHANCING ATM".

[8] ShivendraDwivedi, RanjanaSharma, Pallavi Mishra "A REVIEW ON SECURE ATM BY IMAGE PROCESSING”.

[9] Suganya. T, Nithya. T, Sunitha. C, MeenaPreethi. B "SECURING ATM BY IMAGE PROCESSING- FACIAL RECOGNITION AUTHENTICATION".

[10] Different types of threads in an ATM, www.ncr.com.

[11] Different types of security threats in an ATM, www.ncr.com 